\title{
Consumo infantil: o processo de decisão de compra dos pais
}

\author{
Bruna Zatti \\ Daniel Hank Miri \\ Universidade de Caxias do Sul, Caxias do Sul, RS, Brasil \\ Cassiane Chais \\ Juliana Matte \\ E-mails: bzatti@ucs.br \\ dhmiri@ucs.br \\ cassichais@gmail.com \\ ju.cxs1@gmail.com \\ Paula Patrícia Ganzer \\ ganzer.paula@gmail.com \\ pelayo.olea@gmail.com \\ Pelayo Munhoz Olea
}

Recebido em: 25 jun 2018. Aceito em: 22 set 2018.

DOI: http://dx.doi.org/10.21674/2448-0479.45.685-704

\section{Resumo}

Devido às mudanças ocorridas na configuração das famílias, tais como aumento das separações dos pais, ambos trabalharem fora, e resultando em novos comportamentos de consumo, a criança passou a influenciar o ato de compra. Dessa forma, as crianças ganharam participação no planejamento familiar, com opiniões à respeito das escolhas dos pais. A partir dessa nova configuração das famílias e essa influência causada pela ação das crianças no ato de compra dos pais essa pesquisa teve como objetivo investigar a influência do consumo infantil no processo de decisão de compra dos pais do município de Caxias do Sul - RS. A metodologia da pesquisa envolve a abordagem quantitativa com técnica descritiva e análise estatística dos dados. Por meio desta pesquisa, foi aplicado um questionário a uma amostra de 150 pais de crianças entre seis e doze anos ao saírem das compras em supermercados na cidade de Caxias do Sul - RS. A análise dos resultados demonstrou que o consumidor infantil exerce moderada influência no processo de decisão dos pais nos supermercados e que a opinião das crianças é frequentemente aceita na hora da compra por vontade dos pais.

Palavras-chave: Comportamento. Consumidor infantil. Consumo das crianças. Processo decisório de compra.

\section{Abstract \\ Child consumption: the parent's purchase decision process}

Due to changes in the configuration of families, such as increased parental separations, both work out, and resulting in new consumer behaviors, the child began to influence the buying act. In this way, the children gained participation in family planning, with opinions about the parents' choices. Based on this new configuration of the families and this influence caused by the children 's actions in the act of buying 
the parents, this research had the objective of investigating the influence of the children consumption in the purchasing decision process of the parents of the municipality of Caxias do Sul - RS. The methodology of the research involves the quantitative approach with descriptive technique and statistical analysis of the data. Through this research, a questionnaire was applied to a sample of 150 parents of children between six and twelve years of age when they left supermarket purchases in the city of Caxias do Sul - RS. The analysis of the results showed that the infant consumer exerts a moderate influence in the decision process of the parents in the supermarkets and that the opinion of the children is often accepted at the time of the purchase by the will of the parents.

Keywords: Behavior. Child consumer. Child consumption. Decision making process. Purchase.

\section{Introdução}

Uma área de constante preocupação para qualquer empresa atuar no mercado é o comportamento do consumidor. Isto significa estudar todo "o processo envolvido quando indivíduos ou grupos selecionam, compram, usam ou dispõem de produtos, serviços, ideias ou experiências para satisfazer desejos e necessidades" (SOLOMON, 2016, p.7).

Segundo Bauman (2008) o cenário do consumo vem crescendo constantemente de modo a satisfazer os desejos e necessidades humanas, porém muitas vezes o consumidor não está totalmente satisfeito, passa a desacreditar nos desejos que motivam e busca mais estímulos consumistas a serem induzidos de forma plena no processo. O envolvimento das crianças com as coisas materiais, mídias e imagens desperta o mundo do comércio, onde a criança tem o direito de consumir os produtos que deseja, sendo o principal alvo no mercado de consumo.

Um contexto primário de influência de compra é o supermercado. Estima-se que as crianças acompanhem fisicamente os adultos que fazem compras em $20 \%$ das visitas aos supermercados, com os pais acompanhados por crianças gastando, em média, 25\% a mais (Thomas; Garland, 1993). Em um estudo realizado em 2018 os resultados apontam que os compradores acompanhados por seus filhos não gastam mais do que aqueles que estão desacompanhados, mas sim compram $15 \%$ mais rápido (PAGE et al., 2018). As crianças aprendem com os pais como se tornar um consumidor, mas o processo é bidirecional, porque as crianças também estão ensinando os pais a fazer ou mudar suas opiniões sobre produtos diferentes (SHARMA; SONWANEY, 2014).

A influência das crianças nas decisões dos pais pode ser mais cooperativa do que uma luta. Esta influência pode ocorrer nas decisões de compra de produtos e serviços em uma ampla gama de categorias (BERTOL et al., 2017). As crianças influenciam até um quinto de todas as decisões de compra dos agregados familiares, mas pouco se sabe sobre como esta influência é exercida (PAGE et al., 2018).

Dessa forma, este estudo busca investigar a influência do consumo infantil no processo de decisão de compra dos pais nos supermercados do município de Caxias do Sul - RS. Para o meio acadêmico o estudo pôde contribuir com a apresentação de índices que demonstram a influência do 
consumo infantil na compra realizada pelos seus pais. Os achados podem influenciar no posicionamento mercadológico do comércio destinado a este estudo e até mesmo no comportamento dos pais em relação à influência de seus filhos no ato de compra.

O artigo segue estruturado com o referencial teórico, a metodologia com os procedimentos utilizados para o desenvolvimento da pesquisa, apontando-se o delineamento dos participantes do estudo, processos de coleta e análise dos dados. Em seguida o desenvolvimento da pesquisa, com os resultados obtidos e por último as considerações finais.

\section{Referencial Teórico}

\section{Comportamento do Consumidor Infantil}

A maioria das crianças simplesmente solicita produtos aos pais, de modo a satisfazer seus desejos e necessidades, boa parte delas utiliza variadas táticas comuns como: falar que viu o produto na televisão, afirmar que um amigo já possui o produto ou fazer tarefas de casa em troca da aquisição do bem (GUNTER; FURNHAM, 2001).

Segundo Giglio (2010), as crianças têm estilo, motivos e processos de decisão próprios. O que valorizam nos produtos é muito diferente do que pode ser valorizado em outros grupos. A criança pode desenvolver seu comportamento como consumidora com base em observação no comportamento de seus pais, de outras crianças com quem convive ou mesmo com base nas mensagens que a mídia fornece.

A educação da criança sofreu diversas mudanças com o novo perfil dos pais. Na maioria das famílias ambos os pais trabalham e a educação da criança por vezes é administrada por parentes próximos ou ela tende a ficar mais sozinha, com a companhia das mídias que estimulam cada vez mais seus desejos de consumo. A criança tem contato com o dinheiro a partir do momento em que os pais proporcionam experiências de compra com seu próprio dinheiro para a criança, por meio de mesada, dando à criança noções econômicas (GIGLIO, 2010).

Karsaklian (2012, p. 255) considera que para as crianças, existem somente duas alternativas para uso do dinheiro: "ou se gasta tudo de uma vez ou se guarda o dinheiro que se tem", pois as crianças não conseguem ver o ato de economizar como forma de investimento para uma compra futura.

\section{Características do Consumidor Infantil}

O aprendizado segundo a teoria cognitiva ocorre a partir dos processos mentais, sendo parte do pressuposto que o indivíduo age racionalmente na busca da solução de problemas. Nos processos mentais, que determinam como se aprende e como a informação é transferida para a memória de longo prazo, são estudados as características das crianças, o pensamento e raciocínio de acordo com o comportamento (LIMEIRA, 2008). 
Segundo Balestra (2012) que leva em conta, em sua análise, os estudos de Jean Piaget, existem quatro fases do desenvolvimento da criança, a mesma se desenvolve a partir do momento que começa a interagir por meio de ações cognitivas relacionadas à capacidade de tudo o que aprende, o conhecimento que adquiriu ao longo do tempo. Este processo de desenvolvimento de capacidades de armazenamento e recuperação da informação se inicia na fase de recém-nascido, seguindo até a ao raciocínio formal e pensamento racional adulto. Os estágios ou etapas de transição das crianças são classificados em:

a) primeiro estágio - sensório-motor ( 0 a 2 anos): a criança inicia o conhecimento através de suas próprias habilidades e ações por meio da observação, relaciona informações trazidas de seus sentimentos, sem se deixar influenciar por outras pessoas. A criança aprende sobre si, reflexos e comportamentos aleatórios, começa a ter noções de objetos e espaços;

b) segundo estágio - pré-operatória (por volta dos 3 a 6 anos): a criança aprende a utilizar linguagem e símbolos, com percepção de não aceitação de algumas ideias. Este estágio se caracteriza como egocêntrico e realista, quando a criança enxerga tudo da mesma forma e que tudo deve ter uma explicação concreta a respeito;

c) terceiro estágio - operatória concreta (por volta dos 7 a 11 anos): a criança entra na fase da mudança de percepção sensorial para percepção lógica, sendo menos egocêntrica, as suas capacidades dependem de experiências concretas e objetos, desenvolvendo as noções de tempo;

d) quarto estágio - formal (por volta de 12 anos): a criança consegue compreender suas necessidades, com mudanças gradativas no nível de qualidade ao realizar suas atividades espontaneamente e capacidade de tomar decisões concretas. Nesta fase a criança desenvolve noções de tempo, espaço, casualidade, ordem e velocidade, as estruturas cognitivas alcançam o nível mais elevado de desenvolvimento, aplicando o raciocínio lógico para os problemas.

De acordo com Limeira (2008) a lógica e as formas de pensar de uma criança são diferentes da lógica dos adultos, ou seja, as crianças não pensam e nem interpretam as informações da mesma maneira, a criança não é um adulto em miniatura, apresenta suas características próprias de sua idade.

A forma como muitos pais vêm compensando sua ausência no cotidiano das crianças está afetando no comportamento, justificando de modo a agradá-los e não saber dizer não para evitar brigas. Ambos os pais procuram fazer as vontades das crianças para se certificar que serão amados, acabam obedecendo as crianças para não deixar tristes e traumatizar, assim cedem aos desejos despertados pela mídia (SILVA; VASCONCELLOS, 2012).

O público infantil vem sendo bombardeado por informações que muitas vezes não seriam destinadas a ele, provocando uma maturidade precoce no mesmo. Observa-se que as mudanças sociais, como as novas configurações familiares e o avanço tecnológico são capazes de favorecer o isolamento da criança dentro de casa. Tal isolamento acarretaria na criança uma maior liberdade sobre suas ações, evoluindo para uma autonomia com reforço pela quantidade de informações recebidas pelos meios de comunicação mais acessíveis (VANWESENBEECK; WALRAVE; PONNET, 2017). 


\section{Processo de Decisão de Compra}

Conforme Peter e Olson (2010, p. 162) "o processo de integração por meio do qual o consumidor associa seus conhecimentos e avalia um ou mais comportamentos alternativos para selecionar um, é o principal processo na tomada de decisão do consumidor". Os resultados desse processo de integração é uma escolha cognitiva do plano de decisão.

Churchill Jr. e Peter (2012) ressaltam que é comum os consumidores se perguntarem se a alternativa escolhida é de fato a melhor, normalmente acontece na compra de produtos mais caros, a compra desses produtos pode gerar um sentimento de remorso do comprador, podendo resultar na dificuldade ou impossibilidade de avaliar e expor com segurança se a escolha é correta ou não. A tomada de decisão extensiva no ponto de vista de Churchill Jr. e Peter (2012) é a menos comum, porém este tipo de tomada de decisão envolve a comparação de várias alternativas que são avaliadas de acordo com inúmeras características.

Os consumidores consultam o máximo de informações possíveis, como vendedores, amigos e material de propaganda. Este processo requer um investimento significativo de tempo e esforço, portanto, profissionais do marketing que atendem consumidores empenhados em buscas extensivas, podem proporcionar valor comparando diversas alternativas de acordo com os atributos considerados atrativos aos olhos dos consumidores (PADHI, 2017).

Em concordância, Grewal e Levy (2012) apresentam as etapas pelas quais o consumidor passa no processo decisório de compra:

a. reconhecimento da necessidade: é nesse estágio que o consumidor nota que a imagem do seu carro ou da sua televisão entra num padrão de comparação que o deixa insatisfeito, tornando-o reconhecível a necessidade de melhorar sua experiência e qualidade do estado real;

b. busca de informações: grau de risco percebido associado com a compra do bem ou serviço

c. busca interna: memória em experiências passadas para a decisão de compra;

d. busca externa: o consumidor busca informações fora de sua base de conhecimento para definir a compra;

e. avaliação de alternativas: peneira das escolhas disponíveis e avaliar alternativas, ocorre quando o consumidor está engajado no processo de busca por informação;

f. compra: depois que os consumidores possuem o acesso ao bem, o valor que ele the proporcionará é um forte motivador das decisões de compra;

g. pós-compra: comportamento que envolve clientes reais e não potenciais, no qual profissionais do marketing esperam torná-los leais, dessa forma irá repercutir comentários positivos de boca em boca.

\section{A influência da Criança na Decisão de Compra dos Pais}

As crianças exercem significativa influência em várias decisões de compra. A maior influência corre quando as crianças são as próprias usuárias, como na compra de balas, chocolates e brinquedos, 
ou quando estão diretamente envolvidas, por exemplo, na decisão do local das férias. Quando as crianças possuem mais informações do que os pais, no caso de aparelhos eletrônicos e computadores, as crianças podem exercer máxima influência na escolha de alguns atributos de produtos, referente à cores, estilos, modelos e marcas (LIMEIRA, 2008).

Gunter e Furnham (2001) citam que as crianças pedem frequentemente aos pais que the comprem coisas. Estes pedidos podem cobrir artigos caros e baratos. É mais provável que os primeiros sejam satisfeitos. Na mesma medida, as crianças nem sempre conseguem aquilo que desejam. Os pais têm de fazer o equilíbrio entre o que podem gastar e o custo, em termos de harmonia familiar, de recusar comprar as coisas que os filhos desejam consumir.

Os pesquisadores avaliam que as crianças influenciam diretamente em torno de 453 bilhões de dólares em compras familiares por ano. $O$ autor também relata que a cada dois minutos as crianças dão palpites sobre o que comprar no momento que estão fazendo compras com os pais (SOLOMON, 2016).

Ao tratar das influências parentais aos pedidos das crianças, os pedidos efetuados em casa podem ser adiados ou esquecidos antes de ocorrer o ato da compra. A oportunidade da compra é imediata na loja e o desejo de evitar uma cena de recusar o pedido da criança pesa constantemente na mente dos pais. Eles podem substituir por outra compra, desta forma oferecendo um produto substituto ou adiar a compra (GUNTER; FURNHAM, 2001).

A criança, por sua vez, desempenha vários papéis no processo de compra da família com relação a diversos produtos. Para (SOLOMON, 2016, p. 471), "os profissionais de marketing precisam entender o comportamento dos consumidores, e não o do consumidor individual, já que em muitos casos, mais de uma pessoa se envolve na decisão sobre o que comprar".

Muitas empresas buscam conquistar novos consumidores infantis e manter sempre leais à marca através da publicidade com propagandas adaptadas a cada faixa etária. A idade não é o único elemento responsável pela influência da mídia sobre as crianças, independente da identificação e intenções comerciais da propaganda, o que realmente prende a atenção das crianças a ela são as cores, os movimentos, as músicas, os personagens que compõem a história (KARSAKLIAN, 2012). A avaliação do papel das crianças no processo de tomada de decisão tem sido criticada por estar sendo subestimada (LARSSON; ANDERSSON; OSBECK, 2010).

\section{Metodologia}

A pesquisa quantitativa tem caráter objetivo, qualifica, coleta e trata os dados obtidos através do uso de técnicas numéricas e/ou estatísticas de amostragem, população, etc. Analisa e apresenta resultados por meio de tabelas ou gráficos, e faz análise estatística para abranger grandes grupos (MICHEL, 2015).

A pesquisa também é classificada como descritiva, pois descreve a realidade abordando os aspectos de descrição, registro, análise e a interpretação de fenômenos atuais, avaliando as conexões entre as variáveis ou identificar as causas de eventos específicos (FLICK, 2012). O método adotado 
para levantamento dos dados foi uma survey que, segundo Hair Jr. et al. (2005, p. 150), "é um procedimento para a coleta de dados baseado em questionários".

O questionário foi uma adaptação de Rosa (2007), desenvolvendo questões estruturadas para analisar o nível de influência do consumidor infantil na decisão de compras dos pais. O questionário é composto por dezessete questões, e foi aplicado com 150 participantes entre os meses de abril e maio de 2017, em variados dias da semana para que que a amostra fosse heterogênea. A coleta foi realizada com indivíduos que realizaram suas compras e estavam na saída de diversos supermercados do município de Caxias do Sul - RS. Esses participantes são aqueles que possuem filhos com idade entre seis e doze anos. Foi realizada uma abordagem inicial, onde os pesquisadores se apresentaram e informaram o objetivo da pesquisa, dessa forma foi solicitada a participação do indivíduo na pesquisa, e aplicado o questionário com aqueles que autorizaram.

Conforme Gil (2010, p. 134), "a aplicação do pré-teste ocorre logo depois de concluído o questionário, e a partir de então o instrumento terá validade para realizar o levantamento de coleta dos dados". Sendo assim, foram aplicados dez questionários pré-teste com universitários de Caxias do Sul - RS que possuem filhos com idade entre seis e doze anos, para que fosse validado o instrumento de pesquisa. A fórmula para o cálculo da amostra é a seguinte:

$$
\mathbf{n}=(\mathbf{P} \times \mathbf{Z} / \mathrm{E})^{2}
$$

Onde, "P" indicam as proporções de ocorrência ou de não ocorrência da variável em estudo. Quando não há conhecimento dessas proporções, adota-se $p=0,50$ para que seja possível o cálculo do tamanho da amostra. Em que "Z" é o indicador de qual o nível de confiança da pesquisa, sendo de $96 \%$, o "E" é o erro máximo permitido na realização da pesquisa, o erro amostral é de $8 \%$, que segundo Hair Jr. et al. (2005) o erro amostral permitido varia de $5 \%$ à 10\%. Com esses dados, pode calcular o tamanho da amostra:

$$
n=(0,5 \times 1,96 / 0,08)^{2} ; n=150 \text { elementos }
$$

Segundo Barbetta (2002) a aplicação da fórmula acima ocorre devido a não se saber o tamanho da população, por isso se trabalhou com uma população infinita para alcance dos resultados da pesquisa. A seleção dos participantes foi feita por meio de uma amostragem por conveniência, ou seja, foram escolhidas pessoas disponíveis e dispostas a participar da pesquisa em relação ao tema, de acordo com fatores como disponibilidade, tempo ou conveniência (HAIR JR. et al., 2005).

Após a aplicação do questionário, foi criado um banco de informações no software Excel®, com os dados coletados estatisticamente em planilhas, foram analisados por meio do software estatístico SPSS ${ }^{\circledR}$ (Statistical Package for the Social Sciences), no qual foi possível obter e processar os resultados da pesquisa com exposição dos dados em tabelas e gráficos. 


\section{Resultados e Discussões}

O questionário foi aplicado em pais com filhos na idade de seis a doze anos em supermercados da cidade de Caxias do Sul - RS, com o número total de 150 respondentes. O questionário foi composto por dezessete questões que avaliaram o processo decisório de compra dos pais a partir do consumo infantil, conforme os dados e tabelas abaixo.

Sobre o gênero dos respondentes onde 79 dos respondentes são do sexo feminino que corresponde a $53 \%$ e 71 respondentes são do sexo masculino correspondendo a $47 \%$. Por meio desta análise nota-se que são as mulheres a maioria que realizam as compras nos produtos no supermercado. Os homens são conhecidos por fazerem compras com menos frequência do que as mulheres, e têm menor incidência de serem acompanhados por uma criança quando fazem compras (PAGE et al., 2018).

Destaca-se que sobre o estado civil dos respondentes 30 são solteiros que corresponde a $20 \%$, e 97 respondentes são casados ou união estável sendo com maior predominância de $65 \%$ da amostra, 23 respondentes são divorciados ou separados equivale a $15 \%$ e 0 viúvos igual a $0 \%$.

Referente a faixa etária dos pais destaca-se 81 respondentes entre 30 a 39 anos equivalente a $54 \%, 36$ entre 40 a 49 anos equivalente a $24 \%$. Na Tabela 1 são apresentados os dados da escolaridade dos respondentes.

Tabela 1 - Escolaridade

\begin{tabular}{ccl}
\hline Respondentes & Percentual & \multicolumn{1}{c}{ Respostas } \\
\hline 7 & $4,70 \%$ & Analfabeto/Fundamental incompleto \\
30 & $20 \%$ & Fundamental completo/Ensino médio incompleto \\
88 & $58,70 \%$ & Ensino médio completo/Superior incompleto \\
25 & $16,7 \%$ & Superior completo \\
\hline
\end{tabular}

A partir dos dados da Tabela 1 entende-se que maioria dos respondentes possuem entre ensino médio completo ou superior incompleto e ensino superior completo, fator que pode determinar a faixa da renda familiar, demonstrada na Tabela 2.

Tabela 2 - Faixa de renda familiar

\begin{tabular}{ccl}
\hline Respondentes & Percentual & \multicolumn{1}{c}{ Renda familiar } \\
\hline 4 & $2,70 \%$ & Até $\mathrm{R} \$ 1.000,00$ \\
77 & $51,30 \%$ & De $\mathrm{R} \$ 1.001,00$ a $\mathrm{R} \$ 3.000,00$ \\
60 & $40 \%$ & De $\mathrm{R} \$ 3.001,00$ a $\mathrm{R} \$ 5.000,00$ \\
8 & $5,30 \%$ & De $\mathrm{R} \$ 5.001,00$ a $\mathrm{R} \$ 7.000,00$ \\
1 & $0,70 \%$ & Acima de $\mathrm{R} \$ 7.000,00$ \\
\hline
\end{tabular}

Conforme a Tabela 2 a pergunta sobre a renda familiar, 77 respondentes declaram estar na faixa entre $R \$ 1.001,00$ e $R \$ 3.000,00$ corresponde a $51,30 \%, 60$ respondentes entre $R \$ 3.001,00$ a $\mathrm{R} \$ 5.000,00$ equivale a $40 \%$. Este resultado predominantemente com uma faixa salarial baixa ocorre devido à crise econômica que o país vem enfrentando, com base na teoria econômica do consumidor 
explica que os consumidores tomam decisões de compra e de que forma suas escolhas são influenciadas pelas variações de preço do produto e renda familiar (LIMEIRA, 2008).

Tabela 3 - Ocupação

\begin{tabular}{ccl}
\hline Respondentes & Percentual & \multicolumn{1}{c}{ Respostas } \\
\hline 2 & $1,30 \%$ & Desempregado \\
12 & $8,0 \%$ & Autônomo \\
6 & $4,0 \%$ & Aposentado \\
1 & $0,70 \%$ & Do lar \\
3 & $2, \%$ & Estudante \\
18 & $12 \%$ & Trabalha em empresa pública \\
101 & $67,30 \%$ & Trabalha em empresa privada \\
7 & $4,70 \%$ & Empresário \\
0 & $0 \%$ & Outra \\
\hline
\end{tabular}

A Tabela 3 apresenta o levantamento da ocupação dos pais, e percebe-se que maioria dos respondentes corresponde a 101 pessoas que trabalham em empresa privada no total de $67,30 \%$, 2 estão desempregados que corresponde a 1,30\%, 12 respondentes são autônomos representando $8,0 \%$.

Até esta etapa do estudo, é possível traçar um perfil dos entrevistados na amostra deste estudo: predominam indivíduos com ensino médio completo ou superior incompleto com renda entre $R \$ 1.000,00$ e $R \$ 3.000,00$, que trabalham em empresas privadas, casados e com idade entre 30 e 39 anos.

Figura 1 - Idade dos filhos

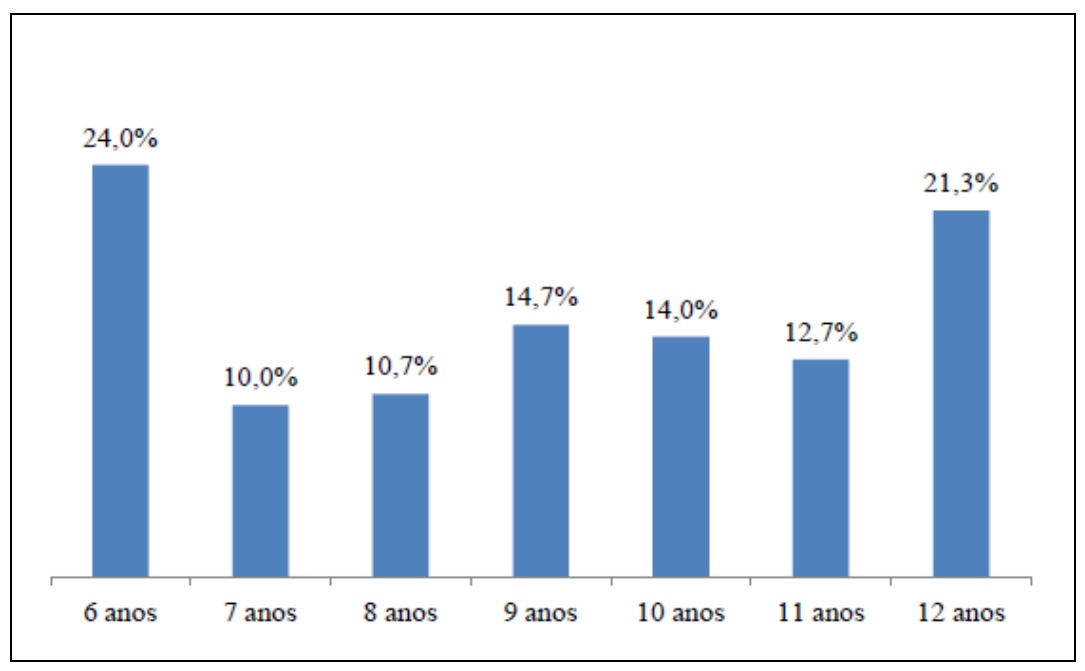

A Figura 1 apresenta os dados relacionados à idade dos filhos. Nesse item, nota-se maior predominância dos pais que possuem filhos com 6 anos de idade, 36 obtendo o resultado de $24 \%$, e a menor taxa de predominância está nos filhos com 7 anos correspondendo a 10\%, sendo 15 respondentes. Conforme a delimitação do estudo a faixa etária dos filhos ficou restrita, variando entre 6 a 12 anos, porque é nesta fase que a criança tende a imitar o consumo dos pais, assumindo um papel ativo como consumidora, quando começa a fazer suas compras sozinha, com análise de quantidade e comparação de preços (SHARMA; SONWANEY, 2014). 
Os pais foram questionados sobre o gênero dos filhos, sendo que aqueles que possuíam mais de um filho deveriam informar o gênero de todos. A maioria dos pais possuem filhos do gênero feminino, sendo 86 crianças, correspondendo a $51 \%$ da amostra, e 81 do gênero masculino equivalente a 49\%.

Tabela 4 - Com quem os filhos moram

\begin{tabular}{ccc}
\hline Respondentes & Percentual & Respostas \\
\hline 95 & $63,30 \%$ & Pais \\
46 & $30,70 \%$ & Mãe \\
5 & $3,30 \%$ & Pai \\
4 & $2,70 \%$ & Avós \\
\hline
\end{tabular}

Conforme a Tabela 4 apresenta-se um resultado significativo dos filhos que moram com os pais, sendo 95 crianças, representando $63,30 \%$ da amostra, 46 residem somente com a mãe, correspondendo a 30,70\%, 5 deles residem com o pai que equivale a 3,30\% e apenas 4 residem com os avós a $2,70 \%$. Os filhos que moram apenas com a mãe é um percentual considerável.

É possível observar na análise que a configuração familiar que se mantém em Caxias do Sul RS, é considerada comum, devido os pais serem casados ou possuem união estável. Constituído por um homem, uma mulher e um ou mais filhos morando no mesmo domicílio, sofre transformações no que diz respeito a um dos pais se fazer ausente, normalmente nos casos onde os pais são solteiros (LIMEIRA, 2008).

Tabela 5 - A frequência que você leva os filhos às compras

\begin{tabular}{ccc}
\hline Respondentes & Percentual & Respostas \\
\hline 2 & $1,30 \%$ & Nunca \\
10 & $6,70 \%$ & Raramente \\
63 & $41,30 \%$ & Algumas vezes \\
30 & $24,70 \%$ & Frequentemente \\
37 & $26 \%$ & Quase sempre \\
\hline
\end{tabular}

Conforme a Tabela 5, foi analisado individualmente cada alternativa referente a frequência que os respondentes levam os filhos às compras, sendo que destaca-se 63 dos pais que levam os filhos "algumas vezes" equivalente a $41,30 \%$, e por último "quase sempre levam" com 37 respondentes que correspondem a $26 \%$. Esse resultado pode ser decorrente da análise da renda familiar que varia entre $\mathrm{R} \$ 1.001,00$ e $\mathrm{R} \$ 3.000,00$. Na grande maioria dos casos observados, em que os pais fazem compra com seus filhos, a interação entre pais e até crianças relativamente pequenas parece ser caracterizada por menos conflitos e mais cooperação e atuação ativa das crianças do que se supunha anteriormente (GRAM, 2015).

Tabela 6 - A frequência que os seus filhos pedem para ir às compras com você

\begin{tabular}{ccc}
\hline Respondentes & Percentual & Respostas \\
\hline 6 & $4 \%$ & Nunca \\
31 & $20,70 \%$ & Raramente \\
44 & $29,30 \%$ & Algumas vezes \\
46 & $30,70 \%$ & Frequentemente \\
23 & $15,30 \%$ & Quase sempre \\
\hline
\end{tabular}


Referente a Tabela 6 , perguntado se "os seus filhos pedem para ir às compras com você", percebe-se que 46 responderam que os mesmos frequentemente pedem para irem junto, num total de $30,70 \%$ da amostra. O autocontrole nas decisões de consumo é relevante durante as compras e consumo. Estas intervenções devem se concentrar em educar os pais ou outros cuidadores primários, porque eles são as mais prováveis pessoas para acompanhar as crianças em tais situações e têm uma grande influência na aprendizagem implícita (BÜTTNER et al., 2014). As crianças influenciam as compras através de suas próprias tentativas e por convite dos pais (CALDERON et al., 2017).

Tabela 7 - A frequência que você solicita a opinião dos seus filhos em relação às compras

\begin{tabular}{ccc}
\hline $\mathbf{N}^{\circ}$ de respostas & Percentual & Respostas \\
\hline 12 & $8 \%$ & Nunca \\
37 & $24,70 \%$ & Raramente \\
54 & $36 \%$ & Algumas vezes \\
39 & $26 \%$ & Frequentemente \\
8 & $5,30 \%$ & Quase sempre \\
\hline
\end{tabular}

Analisando a frequência que os pais solicitam a opinião dos seus filhos em relação às compras, conforme Tabela 7, verificou-se que 12 respondentes "nunca" pedem opinião, que equivale à $8 \%$, "raramente" com 37 que corresponde a 24,70\%, com maior predominância 54 pais "algumas vezes" solicitam a opinião no total de $36 \%, 39$ "frequentemente" que corresponde a $26 \%$, e 8 respondentes "quase sempre" igual a 5,30\%. Mesmo que a criança não esteja junto para dar a opinião diretamente, a maioria dos pais sofre algum tipo de influência, tanto direta ou indireta, pois realiza as escolhas pensando em agradar ao gosto da criança, principalmente quando se refere às compras de supermercado, onde os pais seguem automaticamente o padrão dos gostos das crianças (SHONKOFF et al., 2018).

Tabela 8 - A frequência que os seus filhos dão opiniões sobre as compras espontaneamente

\begin{tabular}{ccc}
\hline Respondentes & Percentual & Respostas \\
\hline 12 & $8 \%$ & Nunca \\
26 & $17,30 \%$ & Raramente \\
53 & $35,30 \%$ & Algumas vezes \\
32 & $21,30 \%$ & Frequentemente \\
27 & $18 \%$ & Quase sempre \\
\hline
\end{tabular}

Em relação à frequência em que os filhos opinam sobre as compras dos pais espontaneamente descrito na Tabela 8, apresenta-se 53 respondentes que "algumas vezes" seus filhos dão opinião, num total de $35,30 \%$ da amostra, 32 "frequentemente" correspondendo a 21,30\%, 27 "quase sempre" que corresponde a 18\%, 26 "raramente" que equivale a 17,30\% e 12 "nunca" dão opiniões $8 \%$. Esse item pode estar atrelado à faixa da renda salarial dos entrevistados, em que a maioria possui uma renda que pode não permitir que os gastos extrapolem sua renda, e uma das maneiras encontradas pode ser a diminuição da frequência com que os filhos participam das compras. A maior parte das crianças costuma prestar atenção na mídia e pedir para os pais comprarem os itens que são divulgados 
(FERRUZZI, 2017). As crianças que solicitam produtos, são mais propensas a simplesmente perguntar ou usar estratégias não-verbais (CALDERON et al., 2017).

Outro item que pode estar atrelado a esta evidência é "A frequência que você aceita a opinião dos seus filhos sobre as compras", em que $40 \%$ dos respondentes declararam que "algumas vezes" aceitam a opinião dos filhos e 10 respondentes declararam que "nunca" aceitam, totalizando $6,7 \%$ da amostra. Porém os estudos de Solomon (2016) indicam que as crianças dão palpites sobre o que comprar e algumas vezes as crianças influenciam nas compras familiares. Os pais valorizam mais às opiniões de seus filhos sobre as decisões de compra, o capitalismo contemporâneo transformou as crianças em pequenos compradores submetidos aos padrões da indústria cultural que altera as características naturais das crianças (ANGELO, 2013). As intervenções parentais são necessárias para promover o estabelecimento de limites ao fazer compras, e estejam cientes de como o envolvimento da criança influencia os resultados de gastos e compras (CALDERON et al., 2017).

Tabela 9 - Qual a reação dos seus filhos quando a opinião não é aceita

\begin{tabular}{ccc}
\hline Respondentes & Percentual & Respostas \\
\hline 51 & $34 \%$ & Reclama, mas aceita \\
65 & $43,30 \%$ & Aceita sem reclamar \\
14 & $9,30 \%$ & Chora \\
0 & $0 \%$ & Grita \\
22 & $14,70 \%$ & Fica bravo \\
\hline
\end{tabular}

Conforme a Tabela 9, a questão compara a reação dos filhos quando a opinião não é aceita e 51 respondentes relatam que os filhos "reclamam, mas aceitam" correspondendo a 34\%, 65 "aceitam sem reclamar" que equivale a 43,30\% da amostra, 14 filhos "choram" que corresponde a 9,30\%, 22 relatam que os filhos "ficam bravos" equivalente a $14,70 \%$ e "grita" foi a reação que não obteve nenhuma resposta.

Os pais conseguem direcionar os filhos para algumas opções pré-escolhidas por eles, passando uma sensação de abertura de espaço, mas na verdade esse espaço é controlado. Negar um pedido da criança vai fazer ela se sentir segura, por mais que não pareça, mas vai ensinar o que pode ou não ser comprado, impondo limites (SILVA; VASCONCELLOS, 2012).

As respostas da Tabela 12 foram sobre o seguinte questionamento: "qual (is) produtos você percebe sofrer maior influência do(s) seu(s) filho(s) na hora da compra?" Pode-se concluir que a maioria, 80 respondentes sofrem influências nos "doces" totalizando $53,30 \%$ da amostra, 60 em "salgados" correspondendo a 40\%, nos "biscoitos" 42 equivalente a 28\%, 43 em "refrigerantes e sucos" que corresponde a $28,70 \%$ e as "frutas" com 12 respondentes possuem menor influência na hora da compra com $5,10 \%$. As dimensões de necessidades de consumo na infância e privações de consumo se mostram associadas (OLIVEIRA, 2016).

Este resultado obtido na Tabela 10 comprova os estudos de Limeira (2008) onde a maior influência que a criança exerce é quando elas são as próprias usuárias do produto, como na compra de balas, chocolates, ou quando estão diretamente envolvidas. Nesta questão não foi medida a 
influência de compra em outros artigos como roupas ou brinquedos porque em alguns supermercados utilizados como base de pesquisa não havia essa opção.

Tabela 10 - Quais produtos você percebe sofrer maior influência dos seus filhos na hora da compra

\begin{tabular}{ccl}
\hline Respondentes & Percentual & \multicolumn{1}{c}{ Respostas } \\
\hline 60 & $40 \%$ & Salgados (salgadinhos) \\
80 & $53,30 \%$ & Doces (balas, chocolates, bolos, etc) \\
42 & $28 \%$ & Biscoitos \\
43 & $28,70 \%$ & Refrigerantes ou sucos \\
12 & $5,10 \%$ & Frutas \\
\hline
\end{tabular}

Em contrapartida, Angelo (2013) argumenta que os filhos ficam menos tempo na presença dos pais e os mesmos tentam compensar a ausência cedendo aos desejos dos filhos. O nível de influência de compra pelas crianças pode persistir na forma como os produtos de referência são usados para a criança no local de compra (PAGE et al., 2018).

Tabela 11 - O que motiva você a levar seus filhos às compras

\begin{tabular}{ccc}
\hline Respondentes & Percentual & Respostas \\
\hline 31 & $20,70 \%$ & Não tenho com quem deixar \\
17 & $11,30 \%$ & Porque o filho pede para ir \\
38 & $25,30 \%$ & Educação financeira \\
63 & $42 \%$ & Porque faço questão da companhia \\
1 & $0,70 \%$ & Outra \\
\hline
\end{tabular}

Conforme demonstra na Tabela 11, observando a questão sobre o que motiva os pais a levarem os filhos as compras, fica bem claro que 63 respondentes fazem "questão da companhia" representando 42\%, 38 por "educação financeira" equivalente a 25,30\%, 31 respondentes "por não ter com quem deixar" o filho correspondendo a 20,70\%, 17 "porque o filho pede para ir" que corresponde a $11,30 \%$ e 1 respondente relata que "por necessidade" equivalente a $0,70 \%$.

Este resultado pode-se levar em conta a forma como os pais vêm compensando sua ausência no cotidiano das crianças, fazendo questão da companhia dos filhos na hora da compra, justificando de modo a agradá-los e se certificar que serão amados (ANGELO, 2013). Os compradores acompanhados não gastam mais do que os compradores desacompanhados, mas sim compram 15\% mais rápido, com tendência a evitar áreas ocupadas no local (PAGE et al., 2018).

Tabela 12 - Qual o fator determinante para você aceitar a opinião dos seus filhos

\begin{tabular}{ccc}
\hline Respondentes & Percentual & Respostas \\
\hline 44 & $29,30 \%$ & Vontade dele(a) \\
90 & $60 \%$ & Sua vontade \\
7 & $4,70 \%$ & Eu não aceito a opinião dele(a) \\
9 & $6 \%$ & Outros \\
\hline
\end{tabular}


Com relação à questão da Tabela 12, ao perguntar qual o fator determinante para você aceitar a opinião dos seus filhos, pode-se observar, que 90 respondentes determinam "sua vontade" e equivalente a $60 \%$ da amostra, 44 como "vontade dele (a)" correspondendo a $29,30 \%$, "eu não aceito a opinião dele (a)" 7 respondentes corresponde a 4,70\%, 9 respondentes abordaram "outros fatores" determinantes, tais como: participar das decisões familiares; conversar e entrar em um acordo; desenvolver auto confiança; mostrar o que pode e não pode; se conhece o produto; vontade mútua, correspondendo a $6 \%$. Segundo a maioria dos respondentes, o fator determinante para aceitar a opinião dos filhos é a sua própria vontade para adquirir um produto.

$\mathrm{Na}$ Tabela 13, correspondente a questão sobre quando seu(s) filho(s) solicita um produto, cuja compra você considera inadequada, sua atitude é "faz a compra, sem discutir" com 24 respondentes, cuja análise equivale a 16\%. Com maior predominância 57 respondentes "substituem a compra por outro item" num total de $38 \%$, em contrapartida 53 "adiam a compra para outro momento" correspondendo a $35,30 \%$, e apenas 6 "ignoram ou rejeitam o pedido" equivalente a $4 \%$. As crianças são influenciadas por opções que são oferecidas a elas, seja na mídia ou no atendimento (SHONKOFF et al., 2018).

Tabela 13 - Quando seus filhos solicitam um produto, cuja compra você considera inadequada

\begin{tabular}{ccc}
\hline Respondentes & Percentual & Respostas \\
24 & $16 \%$ & Faz a compra, sem discutir \\
57 & $38 \%$ & Substitui a compra por outro item \\
53 & $35,30 \%$ & Adia a compra para outro momento \\
6 & $4 \%$ & Ignora ou rejeita o pedido \\
10 & $6,70 \%$ & Outra \\
\hline
\end{tabular}

Dando sequência na análise da Tabela 13, 10 respondentes complementam que quando seus filhos solicitam um produto e a compra for inadequada suas atitudes são bem relativas, verificam se realmente é necessário efetuar a compra de determinado produto, explicam a situação por qual não realizará a compra e o real motivo, em alguns casos não realiza a compra, representando $6,70 \%$ da amostra.

Os pais possuem várias respostas para as solicitações de seus filhos, mas isso não impede a criança de achar novas maneiras de pedir o que quer, para driblar as respostas de seus pais, muitas vezes as crianças solicitam uma compra, mas porque ainda são muito pequenas, não percebem que o objeto em questão é muito caro, de má qualidade ou inapropriado para uma criança, oferecendo um substituto (GUNTER; FURNHAM, 2001). A necessidade de consumo pode ser por causa de aflição, auto realização e exposição (OLIVEIRA, 2016).

A questão da Tabela 14 correlaciona as frases ditas pelos filhos para tentar convencer os pais a comprar um produto, a frase mais falada com 62 respondentes "mas todo mundo tem, menos eu" totalizando $47,70 \%$ da amostra, em segundo "eu vou te pedir só mais uma vez" com 47 respostas que equivale a 36,20\%, 21 respondentes afirmam que "se você não comprar, eu vou pedir para minha vó" representa 16,20\%, "se você comprar para mim, eu vou te amar para sempre" 17 que corresponde a 13,10\% e a menos dita com 2 respondentes "se você não comprar, eu vou fugir de casa" equivalente a 
$1,50 \%$. Outras frases foram citadas pelos pais de modo a tentar convencê-lo a compra, 21 respondentes que corresponde a $14 \%$, sendo as seguintes: "você nunca compra o que eu quero; por favor, por favor; o pai compra; só se você quiser me dar; você é a melhor mãe do mundo; pode ser só um".

Tabela 14 - Quais das frases abaixo são faladas por seus filhos para tentar convencer a comprar um produto

\begin{tabular}{ccc}
\hline Respondentes & Percentual & Respostas \\
\hline 47 & $36,20 \%$ & "eu vou te pedir só mais uma vez" \\
21 & $16,20 \%$ & "se você não comprar, eu vou pedir para minha vó" \\
17 & $13,10 \%$ & "se você comprar para mim, eu vou te amar para sempre" \\
2 & $1,50 \%$ & "se você não comprar, eu vou fugir de casa" \\
62 & $47,70 \%$ & "mas todo mundo tem, menos eu" \\
21 & $14 \%$ & Outras \\
\hline
\end{tabular}

Nas estratégias utilizadas para convencer os pais de comprar o que querem, as crianças podem fazer solicitações, onde podem perceber na análise que os filhos fazem de propósito porque sabem que certos tipos de frases ou gestos podem render gratificações, às vezes de forma direta ou emocional. As crianças se comportam como profissionais de marketing com os seus pais, com suas solicitações tentam atingir as necessidades ou motivações emocionais de seus pais (SILVA; VASCONCELLOS, 2012).

A Tabela 15 mostra qual o nível de influência que os pais sofrem dos filhos com às compras no supermercado, demonstra que 54 respondentes sofrem "moderada" influencia totalizando $36 \%$, 39 "pouca influência" que equivale a $26 \%$, não sofrem "nenhuma" 36 correspondendo a $24 \%, 21$ respondentes com "forte" influência igual a $14 \%$ e nenhum dos pais sofre "total" influência dos filhos.

Tabela 15 - Qual o nível de influência que você sofre dos seus filhos com relação às compras no supermercado

\begin{tabular}{ccc}
\hline Respondentes & Percentual & Respostas \\
\hline 36 & $24 \%$ & Nenhuma \\
39 & $26 \%$ & Pouca \\
54 & $36 \%$ & Moderada \\
21 & $14 \%$ & Forte \\
0 & $0 \%$ & Total \\
\hline
\end{tabular}

A maioria dos pais passa muitas horas fora de casa a trabalho, dedicando poucas horas por dia a seus filhos. Dessa forma, nota-se que as crianças realmente influenciam na decisão de compra, grande parte dos pais considera moderada a influência exercida pelos filhos no processo decisório, os pais têm de fazer o equilíbrio entre o que podem gastar e o custo, em termos de harmonia familiar, de recusar comprar as coisas que os filhos desejam consumir (FERRUZZI, 2017). 


\section{Análise de Dados Cruzados}

Conforme Hair Jr. (2005) a tabulação cruzada dos dados é a distribuição de frequência de respostas de dois ou mais conjuntos de variáveis e comparadas, com a análise qui-quadrado permite testar se há diferença estatisticamente entre as variáveis e o nível de significância.

Tabela 16 - O que os pais fazem quando os seus filhos pedem para ir às compras

\begin{tabular}{cccc}
\hline \multirow{2}{*}{ Frequência } & \multicolumn{2}{c}{ Gênero } & \multirow{2}{*}{ Total } \\
& Feminino & Masculino & \\
\hline Nunca & 4 & 2 & 6 \\
Raramente & 12 & 19 & 31 \\
Algumas vezes & 31 & 13 & 44 \\
Frequentemente & 19 & 27 & 46 \\
Quase sempre & 13 & 10 & 23 \\
\hline Total & $\mathbf{7 9}$ & $\mathbf{7 1}$ & $\mathbf{1 5 0}$ \\
\hline Teste Qui-quadrado & Valor & DF & Asymp. Sig \\
\hline Qui-quadrado de Pearson & $10,998^{\mathrm{a}}$ & $\mathbf{4}$ & 0,027 \\
\hline № de casos válidos & 150 & & \\
\hline
\end{tabular}

A Tabela 16 demonstra o valor qui-quadrado $(10,998)$, que é significativo no nível 0,027 , como ele é menor que 0,05 . Portanto, verificou-se que "algumas vezes" os filhos pedem para ir às compras com a mãe sendo de 31 respondentes e "frequentemente" para ir com o pai 27 respondentes.

As crianças desempenham um papel na compra para a família, mas seus papéis são frequentemente subestimados. Tanto as crianças quanto os pais devem ser considerados como consumidores competentes e incompetentes para entender as negociações sobre os alimentos familiares (GRAM, 2015). A cultura do consumo está presente na sociedade, influenciando as crianças na decisão de compra (MOMO; MARTINEZ, 2017).

Tabela 17 - O que os pais fazem ao solicitarem a opinião dos seus filhos em relação às compras

\begin{tabular}{cccc}
\hline \multirow{2}{*}{ Frequência } & \multicolumn{2}{c}{ Gênero } & \multirow{2}{*}{ Total } \\
\hline Nunca & 7 & 5 & 12 \\
Reminino & Masculino & \\
\hline Algumas vezes & 13 & 24 & 37 \\
Frequentemente & 24 & 30 & 54 \\
Quase sempre & 28 & 11 & 39 \\
\hline Total & 7 & 1 & 8 \\
\hline
\end{tabular}

Teste Qui-quadrado

\begin{tabular}{l|ccc} 
& Valor & DF & Asymp. Sig \\
\hline Qui-quadrado de Pearson & $15,799^{a}$ & 4 & 0,003 \\
\hline № de casos válidos & 150 & & \\
\hline
\end{tabular}


A Tabela 17 demonstra o valor qui-quadrado (15,799), que é significativo no nível 0,003, como ele é menor que 0,05 . Portanto, verificou-se que a mãe solicita "frequentemente" a opinião da criança com 28 respondentes e que 30 respondentes, o pai solicita "algumas vezes" a opinião da criança em relação às compras.

As crianças e os pais influenciam uns aos outros durante as compras de supermercado, e as crianças que estão mais envolvidas têm maior influência sobre as compras (CALDERON et al., 2017).

\section{Conclusões}

As transformações ocorridas na configuração familiar contribuíram para que as crianças tivessem maior participação no consumo. Os filhos acompanham os pais nas compras com maior frequência, como consequência, despertam-se para o mercado consumidor cada vez mais cedo. Deste modo, no decorrer do estudo, buscou-se investigar a influência do consumo infantil no processo de decisão de compra dos pais nos supermercados de Caxias do Sul - RS, assim delimitando a faixa etária dos filhos e entre 06 e 12 anos, o objetivo foi alcançado e pode-se concluir que o assunto consumo infantil gera muitas incertezas aos pais objeto da pesquisa.

Este resultado expressa que a população da pesquisa possui poder aquisitivo razoável e um bom nível educacional, o que não reflete a maior parte da realidade brasileira. Grande parte dos pais entrevistados são casados ou união estável, representando $64,70 \%$ e $20 \%$ solteiros com idade de 30 a 39 anos, onde as famílias são compostas por pais casados e residem no mesmo domicílio, com pelo menos um filho entre 06 e 12 anos, a maioria é menina 58,80\% e 41,20\% menino.

Ao identificar o comportamento do consumidor infantil, observa-se que $41,30 \%$ dos pais algumas vezes levam os seus filhos para fazerem compras e que $30,70 \%$ dos pais afirmam que frequentemente seus filhos pedem para serem levados para fazerem compras. Referente à opinião das crianças sobre as compras, $36 \%$ dos pais algumas vezes pedem a opinião de seus filhos. Porém, 35,30\% das crianças às vezes dão suas opiniões espontaneamente sobre o que os pais devem comprar.

No comportamento do consumidor infantil foi analisada a frequência de aceitação dos pais sobre a opinião dos filhos e $40 \%$ dos pais algumas vezes aceitam, o fator determinante para os pais aceitarem a opinião dos filhos representa $60 \%$ sua vontade de deixar a criança opinar no processo de decisão de compra. Sobre o que os pais fazem quando o seu filho solicita para comprar determinado produto que seja inadequado para o mesmo, $38 \%$ dos pais responderam que substituem a compra por outro item. Porém, foi constatado que $35,30 \%$ adiam a compra para outro momento, a criança possui várias formas de solicitar o seu desejo de compra, sendo assim verificou-se à reação dos filhos quando a opinião não é aceita, a maioria dos pais respondeu que os filhos aceitam sem reclamar, e $34 \%$ reclamam, mas aceita.

A estratégia que a criança utiliza para influenciar ou convencer os pais a comprar um produto fica bem claro nas frases ditas que $47,70 \%$ responderam que seu filho expressa a seguinte frase "mas todo mundo tem, menos eu", e $36,20 \%$ expressa "eu vou te pedir só mais uma vez", porém $14 \%$ 
respondeu "outra". Nestes casos os pais afirmam que alguns filhos ainda não questionam, por ficarem retraídos na hora da compra em tentar convencer.

A análise dos resultados demonstrou que o consumidor infantil exerce moderada influência no processo de decisão dos pais nos supermercados e que a opinião das crianças é frequentemente aceita na hora da compra por vontade dos pais. Pode-se perceber que os pais sofrem maior influência referente alguns produtos na hora da compra, $53,30 \%$ dos filhos influenciam diretamente nos doces (balas, chocolates, bolos, etc.), como comprova a pesquisa.

Conforme o presente estudo, as crianças menores de doze anos são um grande mercado do consumo infantil, a maioria delas ainda não possui dinheiro próprio, mas sabem usar sua influência no processo de decisão de compra dos pais, os quais possuem renda e as vezes estão sensibilizados para as solicitações de seus filhos na hora da compra.

A pesquisa foi importante para compreender como a amostra de 150 pais de Caxias do Sul -RS se relaciona ao consumo infantil, com isso mostrou que esse estudo pode ser ampliado ou aprofundado. Esta pesquisa proporcionou o entendimento do consumo infantil e sua influência na decisão de compra dos pais com os conflitos e concordâncias no ato de compra em um supermercado, relacionado às mais diversificadas características destes consumidores.

Uma proposta para estudos futuros é a de ampliar o questionário e aprofundar mais as questões em relação ao consumo infantil. Esse estudo pode ser feito para poder compreender e analisar melhor como o consumo infantil influência no processo de decisão de compra dos pais, fazer uma pesquisa preliminar só com técnicas de observação, talvez fosse possível perceber e identificar as atitudes e comportamentos das crianças em relação aos seus pais durante a compra. Fazer uma pesquisa por métodos de observação seria mais eficiente, porque permitiria ao pesquisador verificar outros comportamentos dos pais e dos filhos e também como forma de expandir mais os conceitos.

Agradecimentos: O presente trabalho foi realizado com apoio da Coordenação de Aperfeiçoamento de Pessoal de Nível Superior - Brasil (CAPES) - Código de Financiamento 001", conforme PORTARIA № 206, de 4 de setembro de 2018". Agências: CAPES, FAPERGS, CNPQ, UCS. Os autores Daniel Hank Miri e Cassiane Chais receberam bolsa CAPES/PROSUC; Juliana Matte recebeu bolsa FAPERGS/CAPES e Pelayo Munhoz Olea recebeu Bolsa CNPq Nível 1D enquanto redigiram este artigo.

\section{Referências}

ANGELO, J. de S. D. Pequenos compradores: o consumismo e a brincadeira na educação infantil. 2013. Dissertação (Mestrado em Educação) - Pontifícia Universidade Católica de São Paulo, Programa de Pós-Graduacão em Educação, São Paulo, 2013.

BALESTRA, M. M. M. A psicopedagogia em Piaget: uma ponte para a educação da liberdade. Curitiba: Intersaberes, 2012.

BARBETTA, P. A. Estatística aplicada às Ciências Sociais. 5. ed. Florianópolis: UFSC, 2002.

BAUMAN, Z. Vida para consumo: a transformação das pessoas em mercadoria. Rio de Janeiro: Zahar, 2008.

BERTOL, K. E. et al. Young children's influence on family consumer behavior. Qualitative Market Research: An International Journal, v. 20, n. 4, p. 452-468, 2017. 
BÜTTNER, O. B.; FLORACK, A.; SERFAS, B. G. A dual-step and dual-process model of advertising effects: Implications for reducing the negative impact of advertising on children's consumption behaviour. Journal of Consumer Policy, v. 37, n. 2, p. 161-182, 2014.

CALDERON, J. et al. What happens when parents and children go grocery shopping? An observational study of Latino dyads in Southern California, USA. Health Education \& Behavior, v. 44, n. 1, p. 5-12, 2017.

CHURCHILL JR, G. A.; PETER, J.P. Marketing: criando valor para os clientes. 3. ed. São Paulo: Saraiva, 2012.

FERRUZZI, G. A. As representações sociais sobre o consumo infantil de mães e crianças de Alvares Machado e suas relações com a propaganda televisiva. 2017. Dissertação (Mestrado em Educação) - Universidade Estadual Paulista, Programa de Pós-Graduacão em Educação, Presidente Prudente, 2017.

FLICK, U. Introdução à metodologia de pesquisa: um guia para iniciantes. Porto Alegre: Penso, 2012.

GIGLIO, E. M. O comportamento do consumidor. 3. ed. São Paulo: Pioneira Thomson Learning, 2010.

GIL, A. C. Como elaborar projetos de pesquisa. 5. ed. São Paulo: Atlas, 2010.

GRAM, M. Buying food for the family: Negotiations in parent/child supermarket shopping: An observational study from Denmark and the United States. Journal of contemporary ethnography, $v$. 44, n. 2, p. 169-195, 2015.

GREWAL, D.; LEVY, M. Marketing. Série A. 2. ed. Porto Alegre: AMGH, 2012.

GUNTER, B.; FURMHAM, A. As crianças como consumidoras: uma análise psicológica do mercado juvenil. Rio de Janeiro: Instituto Piaget, 2001.

HAIR JR., J. F. Fundamentos de métodos de pesquisa em administração. Porto Alegre: Bookman, 2005.

KARSAKLIAN, E. Comportamento do consumidor. 2. ed. São Paulo: Editora Atlas, 2012.

LARSSON, B.; ANDERSSON, M.; OSBECK, C. Bringing environmentalism home: Children's influence on family consumption in the Nordic countries and beyond. Childhood, v. 17, n. 1, p. 129-147, 2010.

LIMEIRA, T. M. V. Comportamento do consumidor brasileiro. São Paulo: Saraiva, 2008.

Disponível em: <https://integrada.minhabiblioteca.com.br/\#/books/9788502088641/>. Acesso em: 15 mai. 2017.

MICHEL, M. H. Metodologia e pesquisa científica em ciências sociais: um guia prático para acompanhamento da disciplina e elaboração de trabalhos monográficos. 3. ed. São Paulo: Atlas, 2015.

MOMO, M.; MARTíNEZ, A. M. O trabalho pedagógico criativo na Educação Infantil diante da cultura da mídia e do consumo. Educação em Revista, v. 33, 2017.

OLIVEIRA, M. M. de. Mamãe eu quero! Privações de consumo infantil na pobreza relativa. 2016. 148 f. Dissertação (Mestrado em Administração) - Universidade Federal da Paraiba, Programa de PósGraduacão em Administração, João Pessoa, 2016.

PADHI, P. Decision making process for durable products: A case study of two-wheelers in Ganjam. International Journal of Research in Finance and Marketing, v. 7, n. 5, p. 63-70, 2017. 
PAGE, B. et al. Parents and children in supermarkets: Incidence and influence. Journal of Retailing and Consumer Services, v. 40, p. 31-39, 2018.

PETER, J. P.; OLSON, J. C. Comportamento do consumidor e estratégia de marketing. 8. ed. Porto Alegre: AMGH, 2010.

ROSA, L. L. da. A influência do público infantil no comportamento de compra de seus pais. Universidade Federal de Santa Catarina, Florianópolis SC, 2007. Disponível em: <https://tcc.bu.ufsc.br/Adm292087.PDF>. Acesso em: 12 nov. 2016.

SHARMA, A.; SONWANEY, V. Theoretical modeling of influence of children on family purchase decision making. Procedia-Social and Behavioral Sciences, v. 133, p. 38-46, 2014.

SHONKOFF, E. T. et al. Child and parent perspectives on healthier side dishes and beverages in restaurant kids' meals: results from a national survey in the United States. BMC public health, v. 18, n. 1, p. 56, 2018.

SILVA, A. M. D.; VASCONCELLOS, L. R. A criança e o marketing: informações fundamentais para proteger as crianças dos apelos do marketing infantil. São Paulo: Summus Editorial, 2012.

SOLOMON, M. R. O comportamento do consumidor: comprando, possuindo e sendo. 11. ed. São Paulo: Bookman, 2016.

THOMAS, A.; GARLAND, R. Supermarket shopping lists: their effect on consumer expenditure. International Journal of Retail \& Distribution Management, v. 21, n. 2, 1993.

VANWESENBEECK, I.; WALRAVE, M.; PONNET, K. Children and advergames: the role of product involvement, prior brand attitude, persuasion knowledge and game attitude in purchase intentions and changing attitudes. International Journal of Advertising, v. 36, n. 4, p. 520-541, 2017. 